\title{
THE DIFFERENCES BETWEEN FOAM ROLLING EXERCISE AND SWEDISH MASSAGE ON DELAYED ONSET MUSCLE SORENESS PAIN
}

\author{
Ribkhah Arvita Ekaristi, Herdianty Kusuma H, Marti Rustanti
}

Department of Physiotherapy, School of Health Polytechnics, Surakarta

\begin{abstract}
Background: A person who is not used to exercising will feel muscle fatigue after exercising due to excessive intensity outside of his or her habit. This can lead to aches and pains in the muscles known as delayed onset muscle soreness (DOMS), so there is a need for efforts to overcome DOMS. Therefore, this study aimed to examine the effect of foam rolling exercise with Swedish massage on delayed onset muscle soreness (DOMS) pain.

Subjects and Method: The was an experimental study using pre and post test groups without control design. This study was conducted at the department of physiotherapy, School of Health Polytechnics, Surakarta, in August 2019. Total of 34 physiotherapy students were enrolled in this study and divided into 20 students in groups of foam rolling exercise and 20 students in swedish massage. The dependent variable was DOMS pain. The independent variables were rolling exercise and swedish massage. The data of DOMS were collected using VAS. The data were analyzed using Mann-Whitney test.

Results: There were no difference effect between foam rolling exercise and Swedish massage on DOMS pain, and they were statistically significant.

Conclusion: There is no difference in effect between foam rolling exercise and Swedish massage on delayed onset muscle soreness (DOMS) pain. Both of these interventions can be used as options to reduce pain in DOMS.
\end{abstract}

Keywords: pain, delayed onset muscle soreness, foam rolling exercise, swedish massage

Correspondence:

Ribkhah Arvita Eucharist. Poltekkes Surakarta, Department of Physiotherapy. Jl. Captain Adi Sumarmo, Tohudan, Colomadu. Email: ribkhahekaristi@gmail.com 085869122342

The $7^{\text {th }}$ International Conference on Public Health Solo, Indonesia, November 18-19, 2020 | 372 https://doi.org/10.26911/the7thicph.05.04 